\title{
O Comércio Eletrônico como Estratégia Competitiva para a Sustentabilidade Empresarial
}

\author{
Jonas Pereira Galvão ${ }^{1}$; Marcia Maria Leite Lima
}

Resumo: Esse artigo tem como objetivo geral identificar os principais fatores que influenciam os consumidores a optar pelo comércio eletrônico. Para o alcance do mesmo, foi realizada uma pesquisa de opinião pública. A pesquisa conta com uma abordagem quantitativa, descritiva e exploratória, com amostra não probabilística. A pesquisa foi realizada na cidade de Porteiras-CE. O instrumento de coleta de dados aconteceu por meio de um questionário contendo 11 (onze) perguntas, sendo 08 (oito) fechadas e 03 (três) abertas. Como resultados, foram identificados que os preços acessíveis e as promoções influenciam os consumidores a realizarem compras na internet. Percebeu-se também que os serviços prestados pelo comércio eletrônico deixam um pouco a desejar, por conta das informações sigilosas e dados pessoais que são inseridas pelos clientes na internet.

Palavras-chave: E-commerce. Comportamento do Consumidor. Decisão de Compra.

\section{E-Commerce as a Competitive Strategy for Corporate Sustainability}

\begin{abstract}
That article has as general objective to identify the main factors that influence the consumers to choose for the electronic trade. For the reach of the same, a research of public opinion was accomplished. The research bill with an approach quantitative, descriptive and exploratory, with sample no probabilistic. The research was accomplished in the city of Gate-CE. The instrument of collection of data happened through a questionnaire containing 11 (eleven) questions, being 08 (eight) closed and 03 (three) open. As results, were identified that the accessible prices and the promotions influence the consumers to accomplish her/it purchases in the internet. It was also noticed that the services rendered by the electronic trade leave a little to want, due to the secret information and personal data that are inserted by the customers in the internet.
\end{abstract}

Keywords: E-commerce. Consumer behavior. Buying decision.

\section{Introdução}

Na era da informação, há um grande desafio de fazer com que as empresas tenham capacidade de organização e adaptação às rápidas mudanças, em um mercado cada vez mais complexo, dinâmico e turbulento. A organização precisa adotar uma estrutura de gestão flexível, para que haja respostas

\footnotetext{
${ }^{1}$ Graduando no curso de Administração do Centro Universitário Doutor Leão Sampaio, Juazeiro do Norte, jonasgalvai1234@gmail.com;

${ }^{2}$ Especialista em Gestão Estratégica de Pessoas, Centro Universitário Doutor Leão Sampaio, Juazeiro do Norte, Ceará, marcialeite@leaosampaio.edu.br.
}

145 Id on Line Rev. Mult. Psic. V.12, N. 42, Supl. 1, p. 145-161, 2018 - ISSN 1981-1179
Edição eletrônica em http://idonline.emnuvens.com.br/id 
imediatas às necessidades e desejos dos clientes, ou seja, a empresa precisa se estruturar de forma que a qualquer momento esteja apta a mudar ou adaptar as exigências do mercado.

Em contexto de competitividade entre organizações, surge o mercado eletrônico, que pode ser visto como estratégia de oportunidade para alcançar resultados favoráveis frente ao comércio tradicional. Esse modelo de negócio é chamado de comércio eletrônico, uma prática na qual a internet é usada para vender bens e serviços (NOVAES, 2007).

O comércio eletrônico é um tipo de transação comercial que envolve atividades empreendedoras, desempenhadas por uma empresa através de meios eletrônicos, como as redes sociais que possibilitam uma comunicação com os clientes sobre serviços e lançamento de produtos (FAGUNDES, 2009). Diante do exposto, surge a seguinte pergunta: O que influência os consumidores a comprar no mercado eletrônico? Tendo em vista que os preços das lojas virtuais são mais acessíveis, a possibilidade de troca do produto é menos burocrática e existe uma maior variedade da oferta.

Este estudo tem como objetivo geral identificar os principais fatores que influenciam os consumidores optar pelo comércio eletrônico. Seguido dos objetivos específicos: estudar o comércio eletrônico e suas características; identificar o nível de satisfação dos consumidores em relação ao comercio tradicional; identificar os fatores positivos do comércio eletrônico e fazer um estudo comparativo entre os fatores que levam aos consumidores a optar pelo mercado eletrônico. As hipóteses consistem em: Os preços das lojas virtuais são mais acessíveis do que o mercado tradicional, o mercado virtual tem uma maior variedade e a comodidade do consumidor ao escolher o mercado virtual.

$\mathrm{O}$ referido estudo justifica-se pelo interesse pessoal em saber o grau de vantagens do mercado eletrônico frente ao mercado tradicional na cidade de Porteiras-CE. Em interesses acadêmicos, o presente artigo destaca ser fonte de informação rápida e compreensiva a respeito do mercado eletrônico e o mercado tradicional, podendo identificar o que influência os consumidores a comprar no mercado eletrônico. Assim, o artigo trará novos conhecimentos e saberes ao pesquisador, bem como ser um norteador de indicadores de melhoria ou de novas oportunidades de investimentos inovadores. Sendo um informativo para lojas físicas de produtos ou serviços, mostrando as vantagens e desvantagens do mercado eletrônico.

\section{O Comércio e sua Evolução}

O desenvolvimento do comércio ocorreu com o aparecimento da moeda, não sendo este único fator, pois a invenção da escrita, imprensa, bússola, a descoberta de novas terras, o progresso espantoso da indústria, o aparecimento dos veículos e o incremento dos meios de comunicação contribuíram para o desenvolvimento, seguidos pelos processos da troca de produções por outras (FIGUEIREDO, 2009). 
Figueiredo (2009) afirma que a palavra comércio possui diferentes origens, sendo a grega a mais conhecida, originada do latim commercium, junção das palavras "com" que significa algo como junto ou conjunto e "merx/merc" como mercado, local de troca. Dessa forma comércio seria algo como "local de troca onde pessoas se reúnem"

Desde os primórdios da humanidade esse processo de trocas entre bens e serviços vem acompanhando o homem, visto que nos tempos pré-históricos os homens viviam em estado de completa bruteza, aproximando-se do estado do irracional, vagando em bandos dirigidos por um chefe em busca de melhores condições de sobrevivência (NOVAES, 2007).

Segundo Sousa (2018), na antiguidade para um trabalhador ampliar a produção, era necessário que gastasse um número maior de tempo na realização de atividades como a coleta ou produção necessária para certo intervalo de tempo. Apesar de ser uma solução eficiente, esses trabalhadores não tinham condições suficientes para dedicar seu tempo à realização de outras atividades que também integravam o universo de necessidades essenciais. Dessa forma, um trabalhador poderia recorrer aos produtos de outro para que então pudesse satisfazer as suas necessidades (SOUSA, 2018).

Essas trocas comerciais se tornaram cada vez mais complexas, uma vez que, envolviam uma gama maior de produtores, em certas situações, o produto de troca oferecido por um trabalhador não era aquele que atendia às demandas do outro, assim as primeiras atividades comerciais se baseavam em trocas naturais, estipulando livremente a quantidade de produtos que poderiam envolver e as negociações (SOUSA, 2018).

\section{Comércio Eletrônico}

O comércio eletrônico surgiu com o avanço dos meios tecnológicos, objetivando implementações no processo de venda, destacando que este tipo de comércio está cada dia mais perto das pessoas ao utilizar a internet para vender bens e serviços (NOVAES, 2007).

De acordo com o dicionário Aurélio (2018), o comércio como um todo pode ser entendido como a compra, troca e venda de mercadorias, produtos ou valores, como também relações sociais ou de amizades. O comércio eletrônico evoluiu por meio das compras que eram realizadas pelo telefone, fax e televisores, hoje essa forma compra caiu em decadência, por conta da modernização e dos inúmeros mercados eletrônicos existentes (GREGORES, 2006).

A compra e venda de produtos ou serviços no ambiente de mercados digitais são chamados de e-commerce ou comércio eletrônico, que é uma atividade de negociação on-line com o objetivo promover vendas, pontuando ainda a utilização de recursos de sistemas e aplicativos de internet para atender consumidores, permitindo comunicações entre empresa, fornecedores e clientes (IDESIS, 2010). 
$\mathrm{O}$ e-business pode ser entendido como sistemas auxiliadores de negócio, onde há uma troca de informações entre empresas em tempo real, desenvolvendo de maneira mais prática a comunicação, através de sistemas de compra e venda (EUGÊNIO, 2015). No e-commerce existem transações comerciais, marketing, atividades empreendedoras e vendas de bens e serviços, utilizando redes sociais e sites como forma de comunicação entre vendedores e consumidores (FAGUNDES, 2009).

Albertin (2010) afirma que o e-commerce é um meio tecnológico de comunicação e informação entre empresas e consumidores, atenta aos objetivos do negócio, considerando a facilidade dos níveis de acesso e baixos custos vendas. Pode-se dizer, portanto, que o mercado eletrônico é um meio de compra e venda de bens ou serviços, através de computadores ou outros eletrônicos.

\section{Tipos de E-Commerce}

Quando o comércio eletrônico possui sistemas capazes de interagir informações e comunicações entre empresas, são caracterizadas pelo comércio eletrônico como transações comerciais entre organizações, abrangendo a realização de toda a cadeia de valor, envolvendo todos os meios eletrônicos (LIMEIRA, 2007).

Há várias possibilidades de realizar um negócio entre empresas, como a venda de produtos ou serviços, sendo esta relação conhecida por business-to-business (b2b), que é um comércio eletrônico onde há um relacionamento comercial e organizacional, permite que dezenas de companhias se conectem a outras dezenas por meio de redes virtuais (TURBAM; KING, 2004).

Quando ocorre uma venda entre empresa e consumidor, é caracterizado por business-toconsumer (b2c), que segundo Silva, Romani e Melo (2004), a referida modalidade está ligada basicamente ao relacionamento com o cliente, comércio efetuado, empresa produtora e o consumidor final. Já a venda ou serviço prestado entre uma empresa e o governo, é caracterizado como uma relação comercial, a business-to-government (b2g) que ocorre quando uma empresa vende para o governo, uma vez regulamentada com todos os impostos (SAMPAIO, 2017).

Todavia, o comércio tradicionalista que envolve dois consumidores negociando um bem ou serviço, passa a ser caracterizado por consumer-to-consumer (c2c), visto a interação de compra e vendas com consumidores finais (MAKELAINEN, 2006). O comércio eletrônico consumer-to-business (c2b) é uma forma de comércio em que os clientes oferecem a empresas seus serviços (LIMEIRA, 2007).

O uso desse novo mercado identifica uma série de benefícios que ajudam o próprio mercado a crescer, por intermédio dos avanços tecnológicos ao longo dos anos, tornando-se mais conveniente comprar na internet. 


\section{Vantagens e Desvantagens do Comércio Eletrônico}

Nesse segmento de mercado que é caracterizado por comércio eletrônico existem vantagens que faz os consumidores realizem suas compras com um custo baixo, variedade nos bens oferecidos, facilidade de compra e comodidade (VISSOTO; BONIATI, 2013).

No entanto o Serviço Brasileiro de Apoio e Pequenas Empresas - SEBRAE (2014) discute as desvantagens do mercado eletrônico, pontuando a atenção no momento da compra, considerando a ocorrência de hackers com os dados dos cartões de créditos e senhas, os atrasos com entrega e não haver contato com o produto desejado, contudo são colocadas em pauta as vantagens, por exemplo, a comodidade que os clientes encontram em comprar pela internet, acesso e disponibilidade para realizar uma compra a qualquer hora e pesquisar ou comparar preços. $\mathrm{O}$ quadro 01 destaca as vantagens e desvantagens do comércio eletrônico.

Quadro 01: Vantagens e Desvantagens do Comércio Eletrônico.

\begin{tabular}{|l|l|}
\hline \multicolumn{1}{|c|}{ Vantagens } & \multicolumn{1}{c|}{ Desvantagens } \\
\hline $\begin{array}{l}\text { Comodidade ao acesso de MIX de produtos } \\
\text { sem precisar sair de casa. }\end{array}$ & $\begin{array}{l}\text { Demora no tempo de entrega, onde a maioria lojas virtuais não } \\
\text { oferecem uma entrega rápida, como nas lojas físicas. }\end{array}$ \\
\hline $\begin{array}{l}\text { Comodidade na forma do pagamento em } \\
\text { receber o produto em domicilio. }\end{array}$ & $\begin{array}{l}\text { Não há contato físico com o produto desejado, inexistindo a } \\
\text { possibilidade de provar se o produto é do jeito que o cliente } \\
\text { necessita. }\end{array}$ \\
\hline $\begin{array}{l}\text { Acesso ao produto 24 horas por dia e preços } \\
\text { acessíveis. }\end{array}$ & $\begin{array}{l}\text { Fornecimento de informações sigilosas ou dados pessoais. No } \\
\text { entanto as empresas hoje estão investindo fortemente em } \\
\text { segurança virtual para o cliente ter mais segurança para efetuar } \\
\text { a compra. }\end{array}$ \\
\hline
\end{tabular}

Fonte: Adaptado de Albertin (2000), Costa (2016), Ferreira e Pitwak (2009) e Goberto (2012).

Ao compreender sobre as vantagens e desvantagens, frente ao comércio de eletrônico, é necessário compreender também que cada consumidor possui um perfil comportamental de consumo, considerando que o cliente é um ser social, dotado de necessidades e desejos.

\section{Perfil e Comportamento do Consumidor}

Conforme Blackwell, Miniard e Engel (2005) o comportamento do consumidor é definido como uma área que estuda as razões pelas quais as pessoas têm interesse em comprar. Segundo Vieira (2000) comportamento do consumidor é o estudo dos fatores que levam um indivíduo a comprar um produto, compreendendo os processos e as etapas da realização de uma compra.

Os processos de decisões de compra online se da por vários fatores, considerando as mudanças na vida das pessoas, em decorrência as constantes mudanças tecnológicas (CAMMINO, 2014). O quadro 02 apresenta as seis fases do processo de vendas na internet. 


\begin{tabular}{|c|l|}
\multicolumn{2}{l}{ Quadro 02: As Seis Fases do Processo de Venda na Internet. } \\
\hline Primeira fase & $\begin{array}{l}\text { Os clientes são prospectados através de ações direcionadas para cadastro do } \\
\text { público-alvo. }\end{array}$ \\
\hline Segunda fase & $\begin{array}{l}\text { Relacionamentos chamados de leads, que é conhecer os hábitos de compras dos } \\
\text { clientes. }\end{array}$ \\
\hline Terceira fase & Considerações que apresentam os benefícios de serviços e produtos aos clientes \\
\hline Quarta fase & O perfil do consumidor poderá apresentar propostas mais diretas. \\
\hline Quinta fase & A decisão, onde se inicia uma etapa de fechamento da venda. \\
\hline Sexta fase & Fechamento da venda por completo. \\
\hline
\end{tabular}

Fonte: Adaptação de Cammino (2014).

Considerando o exposto no quadro 02, para as empresas atingirem estas fases é necessário compreender que o consumidor é influenciado por fatores relacionados à cultura, classe social, valores familiares, crenças, atitudes, fator psicológico ou pessoal, grupos de referência e marketing (COBRA, 2007). Estes aspectos citados influenciam no processo de tomada de decisão da compra, sendo então de suma importância para as organizações conhecerem o perfil do público-alvo, antes de iniciar um negócio eletrônico.

\section{Processos de Decisão de Compra Online}

De acordo com Rezende (2018), o processo de decisão de compra online está gerando uma tendência de consumo voltado a comodidade ao cliente. No quadro 03 resumem os cinco passos do processo decisório de compra.

Quadro 03: Cinco Passos do Processo Decisório de Compra.

\begin{tabular}{|c|l|}
\hline Primeiro passo & Reconhecimento das necessidades pelo consumidor. \\
\hline Segundo passo & Busca por informações das melhores formas para suprir as necessidades. \\
\hline Terceiro passo & Avaliação das alternativas disponíveis para satisfazer as necessidades. \\
\hline Quarto passo & Realização da compra do produto ou serviço. \\
\hline Quinto passo & $\begin{array}{l}\text { Experiência pós-compra, onde o cliente poderá tomar decisões futuras, caso a } \\
\text { percepção do produto tenha satisfeito a necessidade. }\end{array}$ \\
\hline
\end{tabular}

Fonte: Adaptação de Frasson (2012).

Analisando o quadro 03, pode-se compreender que o processo de compra possui uma sequência lógica de percepção de necessidade, buscar pela oferta disponível no mercado, avaliação, realização da compra e comportamento pós-compra. 


\section{Estratégias de Marketing Digital no Comércio Eletrônico}

Conforme Las Casas (2010) para vender é preciso fazer um planejamento estratégico, analisando fatores internos e externos da organização. Então para que esse processo de venda aconteça é preciso um plano de marketing para atrair clientes, que segundo, destacando que o marketing digital é o mais recomendado para o comércio eletrônico (TORRES, 2010).

Na concepção de Segura (2009), o marketing digital veio como uma forma de comunicação entre organizações e clientes, tendo em vista que por meio das divulgações em internet dos serviços e produtos, alavancaram a capacidade das vendas.

Nota-se que os benefícios do marketing digital para a empresa, estão voltados à execução de campanhas, interações, opiniões de clientes para os bens ofertados, orientação aos futuros consumidores, identificação de empresas fornecedoras e promoção de vendas e comodidade ao cliente (PEÇANHA, 2018).

\section{Logística no Comércio Eletrônico}

Na percepção de Campos (2017) a logística do comércio eletrônico é considerada uma das tarefas mais importantes no processo de logística de uma empresa, onde a satisfação do cliente é fundamental ao receber o produto em casa no tempo e data correta.

A logística do comércio eletrônico é um processo que começa logo no planejamento do negócio, detalhado todos os pontos a ser trabalhado para oferecer ao cliente um serviço de entrega com qualidade, respeitando toda uma cadeia de logística eficiente (CAMPOS, 2017).

Prado (2017) afirma que o processo logístico tem grande relevância nos desempenhos das vendas online, permitindo controle do estoque, calculo de frete, planejamento das vendas e embalagens do produto, vindo a ser fundamental para garantir a boa fidelização do cliente.

Quadro 04: Passos da Logística Para E-commerce.

\begin{tabular}{|c|l|}
\hline Planejamento de vendas e operações. & $\begin{array}{l}\text { O sucesso de uma loja virtual está relacionado ao armazenamento } \\
\text { e envio do produto, pois para vender, é necessário que o produto } \\
\text { esteja disponível. }\end{array}$ \\
\hline Controle de estoque. & $\begin{array}{l}\text { É importante ter planejamento e controle de estoque para que não } \\
\text { fique sem produtos ou acumule mercadorias, sendo necessário } \\
\text { definir uma política de estoque. }\end{array}$ \\
\hline Aplicação da curva ABC & $\begin{array}{l}\text { Adaptação do teorema de Pareto, com o objetivo de aperfeiçoar } \\
\text { e gerenciar estoques. }\end{array}$ \\
\hline Definir indicadores de desempenho. & $\begin{array}{l}\text { São utilizados para avaliar e medir o nível de desempenho dos } \\
\text { processos da empresa. }\end{array}$ \\
\hline Reduzir custos. & $\begin{array}{l}\text { Gastos com embalagens, fretes de mercadorias ou manutenção de } \\
\text { estoques. }\end{array}$ \\
\hline
\end{tabular}

Fonte: Adaptação de Prado (2017). 
O quadro 04 aponta os passos logísticos para o gerenciamento de um e-commerce. De acordo com Ballou (2010) torna-se uma responsabilidade logística, quando o cliente solicita um pedido/produto e este já está disponível e pronto para entrega. Vale salientar que esta função contribui efetivamente para o sucesso da empresa e satisfação dos consumidores.

\section{Metodologia}

Quantos os meios usados para este estudo, optou-se por um estudo de opinião por se tratar em busca de conhecer atitudes, pontos de vista e preferências que as pessoas têm sobre algum assunto, serviço, produto. Como também conhecer interesses, comportamentos, falha entre outros. No âmbito organizacional esta pesquisa tem como objetivo auxiliar em tomadas de decisão (ALMEIDA, 1996).

Para o desenvolvimento deste estudo buscou informações e conhecimentos em fontes bibliográficas como livros, revistas cientificas, artigos e teses. Este artigo possui abordagem quantitativa, visto que avalia uma quantidade de resultados, tornando se necessário identificar os dados obtidos (Gil, 2010). Caracteriza-se também como pesquisa descritiva e exploratória, pois há uma análise de determinada população com o objetivo de identificar possíveis variáveis e visa proporcionar uma flexibilidade na construção das hipóteses, respectivamente (Gil, 2010). A pesquisa contém uma amostra não probabilística, pois a escolha das partes ou elementos da amostra é feita de forma não aleatória e por conveniência.

De acordo com o Instituto Brasileiro Geografia e Estatística - IBGE, a cidade de Porteiras-CE possui 15.061 pessoas. A pesquisa foi aplicada nos principais grupos e locais da referida cidade, com um público de 151 pessoas. A coleta de dados aconteceu por meio de um questionário auto administrado, contendo 11 perguntas distribuídas em objetivas e subjetivas, sendo 08 perguntas fechadas e 03 abertas.

O questionário auto administrado é o instrumento ao qual o pesquisador planeja e limita as questões que requerem respostas objetivas, ou seja, questões cujas respostas são apenas assinaladas em uma folha entregue pelo pesquisador. Em partes, este método é utilizado pela sua característica de simplificar respostas, o que pode aumentar a taxa de devolução de questionários (FOWLER, 2011).

Como procedimento de tabulação e análise dos dados, todas as informações coletadas através dos questionários foram transcritas para o software Excel, posteriormente apresentados em formato de gráficos para uma melhor representação de variáveis estatísticas, como também uma análise mais profunda sobre os aspectos teóricos organizacionais e sociais. 


\section{Análises e Discussões de Resultados}

A coleta de dados foi realizada por meio de questionários com perguntas objetivas e subjetivas para 151 (cento e cinquenta e um) indivíduos, que frequenta o centro da cidade de Porteiras-CE. A pesquisa aconteceu entre os dias 24 de setembro a 09 de outubro de 2018, nos horários de 09 às 11 horas, onde os participantes responderam perguntas sobre a frequência de compras no comércio eletrônico, se já tinham comprado na internet por indicação de alguém, o motivo que levavam eles a comprar em um site de compra online e a percepção dos respondentes sobre as vantagens e desvantagens de comprar na internet. Os gráficos 01 e 02 mostram o gênero e a idade dos participantes da pesquisa.

\section{Gráfico 01: Gênero.}

Masculino Feminina

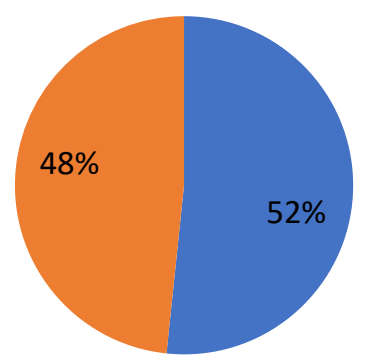

Fonte: Dados da Pesquisa 2018.

No gráfico 01 observar-se que a maioria dos participantes da pesquisa, identificou-se como do gênero masculino, correspondendo a 52\%. Em seguida, $48 \%$ do público enquadraram-se no gênero feminino, com uma diferença mínima os participantes masculinos.

Gráfico 02: Faixa Etária.

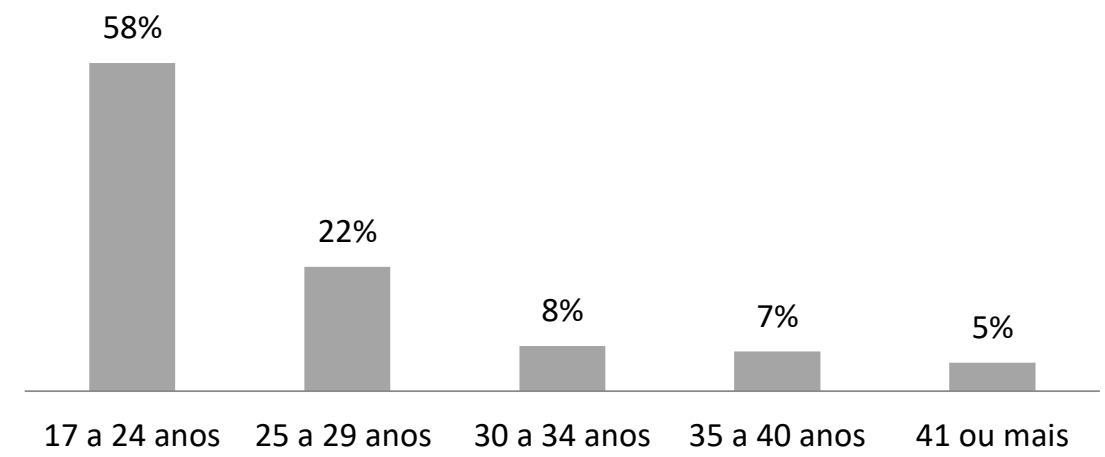

Fonte: Dados da Pesquisa 2018. 
Ao analisar a faixa etária, segundo o gráfico 02 , a idade dos inquiridos varia entre 17 a 41 anos ou mais. Sendo que o intervalo mais frequente foi entre 17 a 24 anos, que corresponde $58 \%$ do total de participantes, seguindo da faixa etária dos 25 a 41 anos ou mais que corresponde aos $42 \%$ restante. $\mathrm{O}$ intervalo menos frequente, com apenas 5\%, foi à faixa etária dos 41 anos ou mais.

Gráfico 03: Você Presta Atenção nos Anúncios e Propagandas das Redes Sociais.

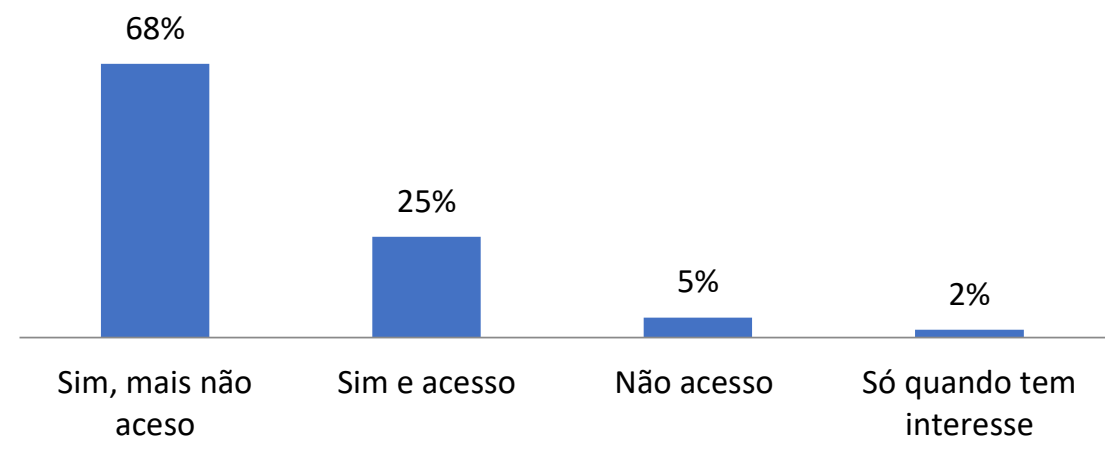

Fonte: Dados da Pesquisa 2018.

No gráfico 03 mostra se os entrevistados percebem os anúncios nas redes sociais, onde $68 \%$ responderam que recebem anúncios nas redes sociais mais que não acessam. Apenas $25 \%$ ver os anúncios nas redes sociais e acessam e 7\% restante não acessam sites ou só quando tem interesse por algum produto ou serviços. Pode alegar que os sites de vendas não estão chamando a atenção dos consumidores para acessar suas plataformas, o que é caracterizado por uma abordagem de marketing digital que de acordo com Segura (2009), o marketing digital veio como uma forma de comunicação entre organizações, utilizando meios da internet para divulgar serviços ou produtos, tentando aumentar a capacidade de venda.

Gráfico 04: Frequência de Compra na Internet.

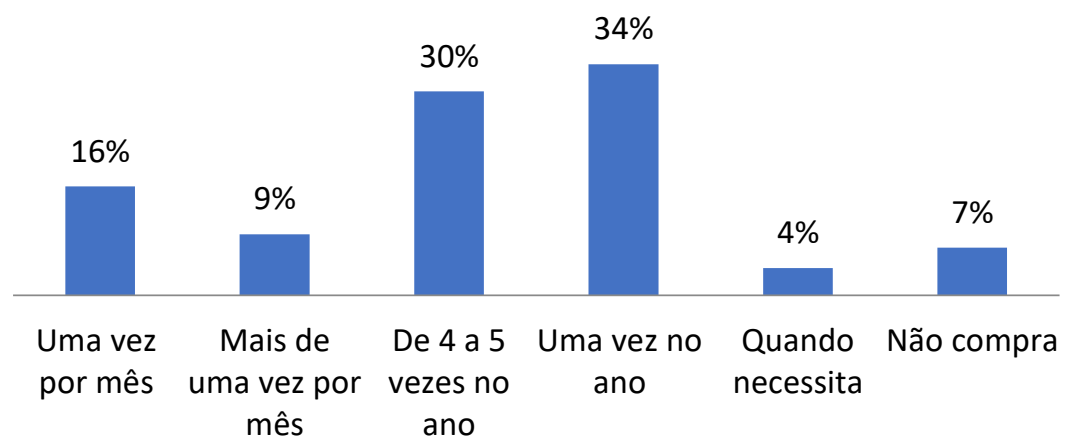

Fonte: Dados da Pesquisa 2018. 
De acordo com os dados coletados e apresentados no gráfico 04, à frequência com que os respondentes compram na internet, corresponde a uma compra pelo menos uma vez no ano (34\%). Notase que $30 \%$ efetuam compras de 04 a 05 vezes por ano. Ainda 16\% dos entrevistados fazem uma compra por mês e $9 \%$ mais de uma vez por mês. Porém 11\% dos entrevistados não compram na internet.

Gráfico 05: Vantagens de Comprar na Internet.

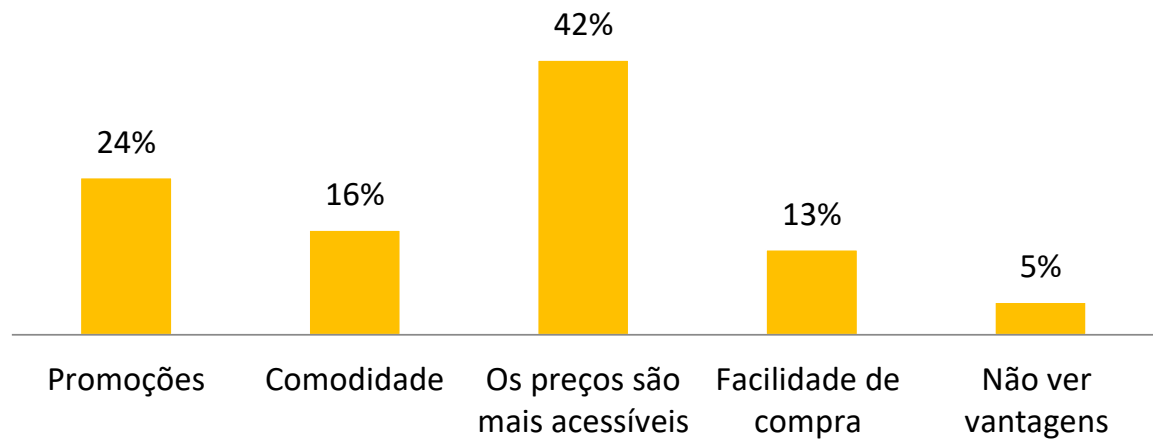

Fonte: Dados da Pesquisa 2018.

O gráfico 05 , apresenta a relação dos fatores que motivam as compras no e-commerce, os participantes apontaram as seguintes opções: $42 \%$ preços mais acessíveis que os das lojas físicas, confirmando a ideia que o consumidor busca por melhores preços; $24 \%$ promoções; $16 \%$ comodidade; $13 \%$ facilidade de compra e $5 \%$ não ver vantagens em comprar na internet. As vantagens citadas, estão de acordo com o que mencionam Albertin (2000), Costa (2016), Ferreira e Pitwak (2009) e Goberto (2012).

Gráfico 06: Compra em Loja Online por Indicação de Alguém.

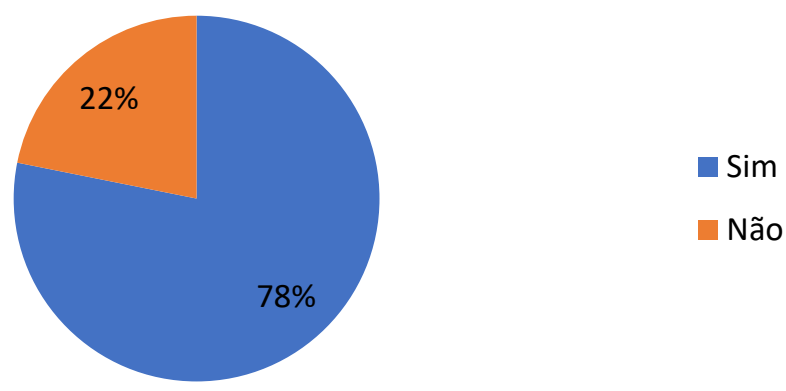

Fonte: Dados da Pesquisa 2018.

No Gráfico 06. Indica quem já adquiriu algum bem ou um serviço online. $78 \%$ dos participantes falaram que compraram na internet por indicação de alguém, no entanto $22 \%$ dos respondentes 
apontaram que nunca realizaram compras por indicação. Percebe-se que as pessoas estão interagindo entre si em relação às compras, considerando fatores descritos no gráfico 05 , onde $42 \%$ das pessoas adquirem produtos online por conta dos preços mais acessíveis e $24 \%$ por causa das promoções. É nítido que houve interação entre consumidores por conta destes quesitos, preços e promoções, relevantes para comprar em lojas online.

Gráfico 07: Desvantagens de Comprar na Internet.

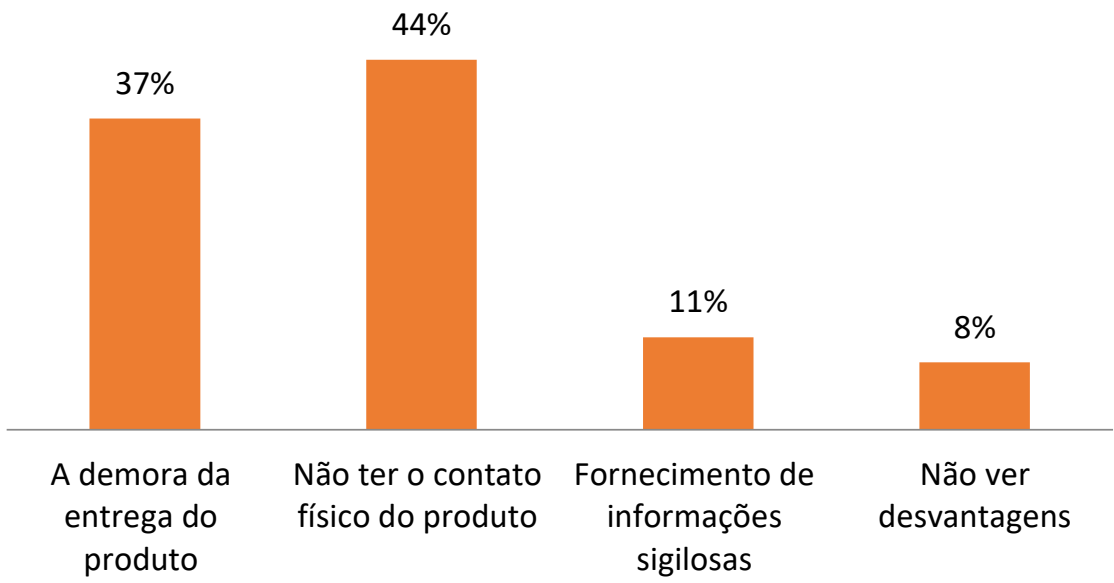

Fonte: Dados da Pesquisa 2018.

No gráfico 07 correspondem as desvantagens de comprar na internet, onde $44 \%$ dos respondentes identificaram a falta de contato com o produto antes da compra, sendo este um fator desestimulante. Nesse tipo de comércio não tem o contato físico diretamente com o produto desejado ou provar se o produto é do jeito que o cliente deseja, por conta disso surgem dúvidas se o produto tem as características necessárias para supri à necessidade que o cliente deseja no momento.

Em seguida $37 \%$ falaram que a demora da entrega do produto é um fator desvantajoso para se comprar na internet. $11 \%$ dos respondentes citaram que o fornecimento de informações sigilosas é um problema, pois cria um desconforto na hora da compra. Costa (2016) menciona que o fornecimento de informações sigilosas, dados pessoais, senhas do cartão de crédito, endereço, número do RG e CPF, entre vários documentos necessários para efetuar uma compra na internet, provocam receio ao consumidor.

No entanto as empresas hoje estão investindo fortemente em segurança virtual para o cliente ter mais segurança para efetuar a compra. 8\% não consegue visualizar desvantagens nesse tipo de negócios. Estas desvantagens pontuadas pelos participantes da pesquisa estão de acordo com mesmas as citadas por Albertin (2000), Costa (2016), Ferreira e Pitwak (2009) e Goberto (2012). 
Gráfico 08: O Que Mais Compra na Internet.

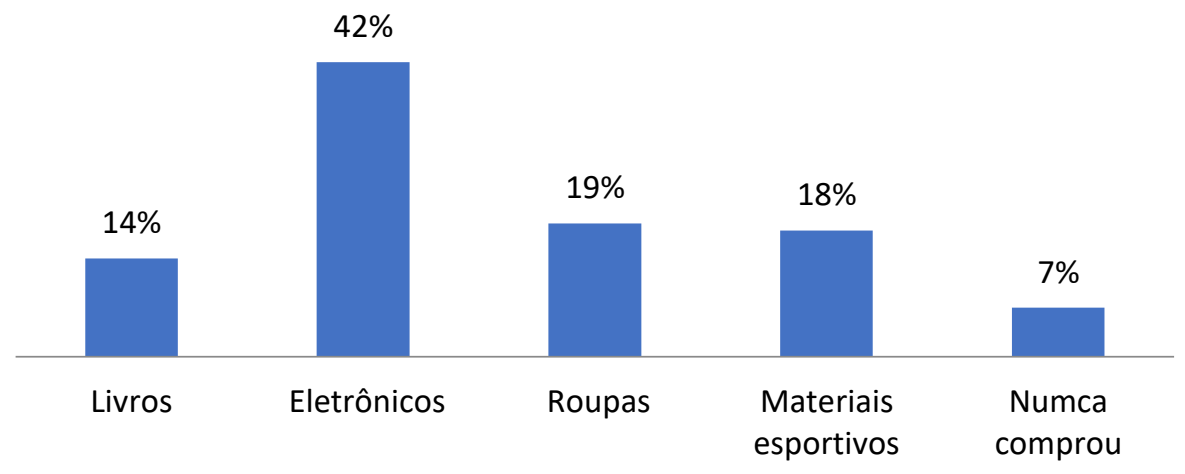

Fonte: Dados da Pesquisa 2018.

O Gráfico 08 demostra o que os entrevistados mais compram na internet. A maioria com $42 \%$ falaram que compram produtos eletrônicos. Um percentual de 19\% optou pela_opção de roupas. 18\% citaram a compra de materiais esportivos. $14 \%$ mencionam a compra de livros. Como já mencionado no gráfico $04,7 \%$ dos entrevistados não compram na internet.

Em relação às perguntas abertas, foram inqueridos aos entrevistados os seguintes questionamentos:

- O que leva você a não gostar de um site de compra?

- Você se sente seguro em comprar na internet?

- Pra você a loja física é melhor do que a loja online?

Para a pergunta 01 a maior predominância dos respondentes foi em relação a falta de segurança. burocracia, demora na entrega do produto, falsas informações e o frete.

Em relação a pergunta 02 os resultados são contraditórios a pergunta 01 , pois a maioria dos respondentes afirmaram que se sentem seguros em comprar pela internet.

E por último as perguntas 03 em sua maioria confirmam que a opção de comprar na loja física é bem melhor que a loja online.

\section{Considerações Finais}

O comércio eletrônico se desenvolveu em larga escala ao longo dos anos. Com a expansão da internet e das novas tecnologias, houve uma evolução do comércio eletrônico. Os consumidores estão cada vez mais utilizando a internet, procurando sites para comprar produtos e serviços, conferindo preços e promoções, fazendo comparações entre a loja online com o mercado tradicional. Vale ressaltar que os consumidores estão buscando comodidade e satisfação em comprar sem sair de casa. 
A pesquisa teve como objetivo geral identificar os principais fatores que influenciam os consumidores a optar pelo mercado eletrônico, relacionado com a pergunta de partida que saber o que influenciava os consumidores a comprar no mercado eletrônico. Sendo esta respondida de maneira satisfatória ao identificar que os preços mais acessíveis (42\%) e as promoções (24\%) eram as maiores influências.

Contudo foram apontados no estudo fatores desvantajosos, por exemplo, não ter o contato físico com o produto. Um fator para se questionar são as propagandas, visto que nas em redes sociais, os entrevistados veem os anúncios mais não acessam. Neste caso as empresas precisam trabalhar o marketing digital, chamando os consumidores para verificar os produtos e serviços oferecidos.

A pesquisa mostrou resultados de grande importância para empresas tradicionais e operantes do mercado eletrônico, podendo ser criado sistemas voltados para as questões de confiança do cliente, em relação a colocar dadas pessoais em sites de compras, levando em consideração que este fator é desmotivador para clientes.

Ao fazer o estudo da pesquisa é notório que os objetivos foram alcançados, onde foram realizados com total importância, deixando bem claro através de estudos teóricos que o que leva os consumidores a compra no mercado eletrônico são os preços mais baixos e promoções. Também de acordo com hipóteses um dos fatores que desmotiva o consumidor e a demora na entrega do produto.

$\mathrm{O}$ artigo mostra a situação atual do mercado eletrônico, conhecido como e-commerce e o mercado tradicional, comparando com os fatores que levam aos consumidores a optar pelo mercado eletrônico. Com a aplicação da coleta de dados, pode-se compreender por meio das diferentes opiniões, a percepção sobre o mercado eletrônico na cidade de Porteiras-CE. Para futuros estudos, fica a sugestão de pesquisas voltadas a melhoria do e-commerce para clientes.

\section{Referências}

ALBERTIN, A.L. Comércio Eletrônico: Modelo, aspectos e Contribuições de sua aplicação. 6. ed. São Paulo: Atlas S.A, 200. 274 p.

ALMEIDA, Maria Lucia Pacheco de . Tipos de Pesquisa. In. Como Elaborar Monografia. 4. Ed. Rev. Estual. Belém: Cejup. 1996. Cap. 4, p. 101-110.

COBRA, M. Marketing Básico: uma perspectiva brasileira. 4.ed. São Paulo: Atlas, 2007

CHING, H. Y. Gestão Estratégica de Estoques na Cadeia de Logística Integrada. 4. ed. São Paulo: Atlas, 2010.

DICIONÁRIO do Aurélio. 2018. Disponível <https://dicionariodoaurelio.com/comercio〉. Acesso em: 25 mar. 2018. 
FAGUNDES, E. O que é E-commerce. 2009. Disponível em: <http://efagundes.com/artigos/o-quee-e-commerce/>. Acesso em: 25 mar. 2018.

FOWLER, Floyd. Pesquisa de Levantamento. 4. ed. Porto Alegre: Penso, 2011.

GIL, Antônio Carlos. Como Elaborar Projeto de Pesquisa. 5. ed. São Paulo: Atlas, 2010.

GREGORES, Valéria E de M. Compra e Venda Eletrônica e suas Implicações. São Paulo: Método, 2006.

IDESIS, Leandro. E-commerce e E-business. 2010. Disponível em:

<http://www.ebah.com.br/content/ABAAAA9iEAK/comercio-eletronico>. Acesso em: 25 mar. 2018.

LIMEIRA, Tania M. Vidigal. E-Marketing: O Marketing na Internet com Casos Brasileiros. 2. ed. São Paulo: Saraiva, 2007.

NAKAMURA, Rodolfo Reijiro. E-Commerce na Internet: Fácil de Entender. São Paulo: Érica, 2001.

NOVAES, Antônio Galvão. Logística e Gerenciamento da Cadeia de Distribuição: Estratégia, Operação e Avaliação. 4. ed. São Paulo: Campus, 2007.

SILVA, J. C.; ROMANI, R.; MELO, I. E. Comércio Eletrônico: Modelos de Negócios na Internet. 2004.

TASSABEHJI, R. Applying. E-commerce in Business. 1. ed. London: SAGE Publications Limited, 2003.

TEIXEIRA, Jayme Filho. Comercio Eletrônico. Senac Nacional. 2001. ISBN 85-8786-408-4

TURBAN, Efraim., KING, David. Comércio Eletrônico Estratégia e Gestão. São Paulo: Prentice Hall, 2004

PITWAK, Ana Carolina e FERREIRA, Camila Lopes. A Utilização do E-commerce Como Diferencial das Organizações Para a Conquista de Mercado. 2009.

SERRA, C. B. R. O Comércio Eletrônico e suas Implicações na Indústria de Software. Monografia de Bacharelado, Instituto de Economia, Universidade Federal do Rio de Janeiro, 1999.

ALBERTIN, A. L. Comércio Eletrônico Modelo Aspectos e Contribuições. São Paulo: Atlas, 2000.

GOBERTO, M. Desvantagens do Comércio Eletrônico. 2012. Disponível

em:<https://ecommercenews.com.br/artigos/cases/desvantagens-do-comercio-eletronico>. Acesso em:04 maio. 2018. As 11:20

COSTA, F. E-COMMERCE: Vantagens e Desvantagens. 2016. Disponível em:<http://www.administradores.com.br/artigos/empreendedorismo/e-commerce-vantagens-edesvantagens/100697/>.Acesso em: 04 maio.2018 as 11:51

VIEIRA, Valter Afonso. Comportamento do Consumidor. 6.ed. Rio de Janeiro: LTC, 2000. 
CAMMINO, Entenda o Processo de Decisão e Compra dos Consumidores Online. 2014. Disponível em < http://www.cammino.com.br/blog/entenda-o-processo-de-decisao-e-compra-dos-consumidoresonline/>. Acesso em: 04 maio. 2018.

REZENDE, Fatores Influenciadores nas Decisões de Consumo. 2013. Disponível em $<$ http://www.implantandomarketing.com/fatores-influenciadores-nas-decisoes-de-consumo/>. Acesso em: 05 maio. 2018.

FRASSON, Decisão de Compra do Cliente: 5 Passos Para Saber Como ele Ocorre. 2012. Disponível em <http://www.comunicacaoetendencias.com.br/decisao-de-compra-do-cliente-5-passos-para-sabercomo-ela-ocorre>. Acesso em: 05 maio 2018.

SAMARA, Beatriz Santos; MORSCH, Aurélio. Comportamento do Consumidor: Conceitos e Casos. São Paulo: Pearson Prentice Hall, 2005.

BLACKWELL, R. D.; MINIARD, P. W.; ENGEL, J. F. Comportamento do Consumidor. São Paulo: Pioneira Thomson Learning, 2005.

LAS CASAS, Administração de Marketing: Conceitos, Planejamento e Aplicações à Realidade Brasileira. São Paulo: Atlas, 2010.

TORRES, Claudio. Guia Prático de Marketing na Internet para Pequenas Empresas. 2010.Ebook.Disponívelem<http://www.cairu.br/biblioteca/arquivos/Marketing/Marketing_Internet_T ORRES.pdf> Acesso em 12 maio 2018 as 15:00

SEGURA, M. C. O estudo do Marketing Digital versus Marketing Tradicional e a Percepção das suas Campanhas por Parte dos Consumidores no Mercado Virtual a Tradicional. 2009. f. 51. Dissertação (Mestrado em estatística e Gestão da Informação) - Instituto Superior de Estatística e Gestão de Informação da Universidade Nova de Lisboa, Lisboa,2009.

PEÇANHA, V. O que é Marketing Digital. 2018. Disponível em <https://marketingdeconteudo.com/marketing-digital/\#02>. Acesso em: 12 maio 2018.

CAMPOS, R. Como Estruturar a Logística Para o Meu E-commerce. 2017. Disponível em $<$ https://ecommercenews.com.br/artigos/dicas-artigos/como-estruturar-a-logistica-para-o-meu-ecommerce/>. Acesso em: 12 maio 2018.

PRADO, M. Logística Para E-commerce: guia completo para uma gestão eficaz. 2017. Disponível em $<$ https://www.mandae.com.br/blog/logistica-para-e-commerce-guia-completo-para-uma-gestaoeficaz/>. Acesso em: 12 maio 2018.

BALLOU, Ronald H. Logística Empresarial: Transportes, Administração de Materiais e Distribuição Física. 1 ed. São Paulo: Atlas S.A., 2010.

SEBRAE, N. Vantagens e desvantagens do comércio eletrônico. Disponível em <http://www.sebrae.com.br/sites/PortalSebrae/artigos/vantagens-e-desva, 3e8a438af1c92410VgnVCM100000b272010aRCRD> . Acesso em: 14 maio 2018.

SAMPAIO, D. Tipos de e-commerce. 2017. Disponível em <https://marketingdeconteudo.com/tiposde-ecommerce/>. Acesso em: 14 maio 2018. 
EUGÊNIO, M. E-Business o que é. 2015. Disponível em < $\underline{\text { https://www.dlojavirtual.com/como-vender/e- }}$ business-o-que-e>. Acesso em: 30 maio 2018.

FIGUEIREDO, Iria $\quad$ Luppi. 2009. $<$ http://www.oficinadanet.com.br/artigo/1718/historico do comercio eletronico $>$. Acesso em: 06 jun. 2018.

\section{Como citar este artigo (Formato ABNT):}

GALVÃO, Jonas Pereira; LIMA, Marcia Maria Leite. O Comércio Eletrônico como Estratégia Competitiva para a Sustentabilidade Empresarial. Id on Line Rev.Mult. Psic., 2018, vol.12, n.42, Supl. 1, p. 145-161. ISSN: 1981-1179.

Recebido: 02/11/2018;

Aceito: 05/11/2018 